\title{
Induction of Salmonella pathogenicity island 1 under different growth conditions can affect Salmonella-host cell interactions in vitro
}

Correspondence

Olivia Steele-Mortimer omortimer@niaid.nih.gov

Received 18 July 2009

Revised 15 December 2009

Accepted 17 December 2009

\author{
J. Antonio Ibarra, ${ }^{1}$ Leigh A. Knodler, ${ }^{1}$ Daniel E. Sturdevant, ${ }^{2}$ \\ Kimmo Virtaneva, ${ }^{2}$ Aaron B. Carmody, ${ }^{3}$ Elizabeth R. Fischer, ${ }^{4}$ \\ Stephen F. Porcella ${ }^{2}$ and Olivia Steele-Mortimer ${ }^{1}$
}

${ }^{1}$ Laboratory of Intracellular Parasites, Rocky Mountain Laboratories, National Institute of Allergy and Infectious Diseases, National Institutes of Health, Hamilton, MT 59840, USA

${ }^{2}$ Genomics Unit, Rocky Mountain Laboratories, National Institute of Allergy and Infectious Diseases, National Institutes of Health, Hamilton, MT 59840, USA

${ }^{3}$ Flow Cytometry Unit, Rocky Mountain Laboratories, National Institute of Allergy and Infectious Diseases, National Institutes of Health, Hamilton, MT 59840, USA

${ }^{4}$ Microscopy Unit, Rocky Mountain Laboratories, National Institute of Allergy and Infectious Diseases, National Institutes of Health, Hamilton, MT 59840, USA

\begin{abstract}
Salmonella invade non-phagocytic cells by inducing massive actin rearrangements, resulting in membrane ruffle formation and phagocytosis of the bacteria. This process is mediated by a cohort of effector proteins translocated into the host cell by type III secretion system 1, which is encoded by genes in the Salmonella pathogenicity island (SPI) 1 regulon. This network is precisely regulated and must be induced outside of host cells. In vitro invasive Salmonella are prepared by growth in synthetic media although the details vary. Here, we show that culture conditions affect the frequency, and therefore invasion efficiency, of SPI1-induced bacteria and also can affect the ability of Salmonella to adapt to its intracellular niche following invasion. Aerobically grown lateexponential-phase bacteria were more invasive and this was associated with a greater frequency of SPI1-induced, motile bacteria, as revealed by single-cell analysis of gene expression. Culture conditions also affected the ability of Salmonella to adapt to the intracellular environment, since they caused marked differences in intracellular replication. These findings show that induction of SPI1 under different pre-invasion growth conditions can affect the ability of Salmonella to interact with eukaryotic host cells.
\end{abstract}

\section{INTRODUCTION}

Type III secretion systems (T3SS) are important virulence determinants for many Gram-negative pathogens. These systems consist of a specialized secretion apparatus that translocates effector proteins from the bacterial cytoplasm into the host cell. Translocated T3SS effector proteins effectively allow the bacteria to 'hijack' many essential

Abbreviations: aer-LL, Salmonella grown with aeration to late exponential phase; FDR, false discovery rate; GSEA, gene set enrichment analysis; p.i., post-infection; PFA, paraformaldehyde; qPCR, quantitative PCR; SCV, Salmonella-containing vacuole; SPI, Salmonella pathogenicity island; $\mu$ aer-ST, Salmonella grown without aeration to stationary phase; T3SS, type III secretion system; WT, wild-type.

The microarray data discussed in this paper are available from the $\mathrm{NCBI}$ GEO database under accession number GSE13343.

Four supplementary figures and a supplementary table are available with the online version of this paper. intracellular processes. Salmonella enterica serovar Typhimurium ( $S$. Typhimurium) is a facultative intracellular pathogen that causes gastroenteritis in humans and a systemic typhoid-like disease in susceptible mice. S. Typhimurium virulence is dependent on two T3SS (T3SS1 and T3SS2) that are used for invasion of non-phagocytic host cells and modification of the intracellular environment. T3SS1 translocates effector proteins required for invasion of non-phagocytic host cells and some post-invasion events [for a review, see the paper by McGhie et al. (2009)]. In contrast, T3SS2 is induced intracellularly and its effectors are translocated into the host cell across the membrane of the Salmonella-containing vacuole (SCV), a modified phagosome within which the bacteria survive and replicate (Steele-Mortimer, 2008b). Most of the genes encoding T3SS1 and T3SS2 structural components as well as many regulatory factors and effectors are located on Salmonella pathogenicity islands (SPIs) 1 and 2, respectively, although 
some effector proteins are encoded on other pathogenicity islands or islets (Hansen-Wester \& Hensel, 2001; Marcus et al., 2000).

Various environmental signals such as oxygen concentration, osmolarity and bacterial growth state have been shown to influence the expression of SPI1 genes and the secretion of T3SS1 effectors (Ellermeier \& Slauch, 2007). A number of in vitro culture conditions for obtaining SPI1induced invasive $S$. Typhimurium have been described. In aerated culture, the invasive phenotype is induced during a brief period at the end of exponential growth, or late exponential phase (Song et al., 2004; Steele-Mortimer et al., 1999), although other studies have shown that oxygenlimiting, or microaerophilic, conditions are required for optimal induction and that, under these conditions, invasiveness is induced during stationary phase (Bajaj et al., 1996; Behlau \& Miller, 1993; Jones \& Falkow, 1994; Lee \& Falkow, 1990; Schiemann \& Shope, 1991; Temme et al., 2008).

In this study, we have grown $S$. Typhimurium under two distinct 'invasion-inducing' conditions and then analysed gene expression and the ability of the bacteria to invade and replicate within cultured epithelial cells. Bacteria were grown in Luria-Bertani (LB)-Miller broth, either to lateexponential phase with aeration (aer-LL) (Steele-Mortimer et al., 1999) or to stationary phase in the absence of aeration under microaerophilic conditions ( $\mu$ aer-ST). AerLL bacteria were more invasive than $\mu$ aer-ST bacteria and, although transcriptome analysis did not reveal significant variation in SPI1 expression, single-cell analysis revealed differences in frequency of SPI1-induced bacteria, which were predominant in the aer-LL culture. Moreover, coexpression of flagella and SPI1 genes was associated with higher invasion levels. Finally, we found that intracellular replication could be affected by pre-invasion growth conditions and this was associated with differences in intracellular expression of SPI1 genes. Altogether, this study suggests that pre-invasion growth conditions used to induce invasive bacteria in vitro can be an influential factor in the outcome of Salmonella-host cell interactions.

\section{METHODS}

Bacterial cultures and growth conditions. S. Typhimurium SL1344 (Hoiseth \& Stocker, 1981) was used in all experiments unless otherwise indicated. $\triangle \mathrm{SPI} 1: \mathrm{kan}$ has been described previously (Drecktrah et al., 2006). The flagellar mutants fliC::Tn 10, $f l j:$ : Mud-Cm and $f l g B:: \operatorname{Tn} 10$ and the fimAICDHF:: kan mutant were obtained by P22 transduction of S. Typhimurium SL1344 with phages kindly provided by Ed Miao (Miao et al., 2006) and Andreas Bäumler (Weening et al., 2005). Bacteria were initially streaked on LB-Miller agar (10 g tryptone $1^{-1}, 5 \mathrm{~g}$ yeast extract $1^{-1}, 10 \mathrm{~g}$ $\left.\mathrm{NaCl} 1^{-1}, \mathrm{pH} 7.0\right)$ supplemented with streptomycin $\left(100 \mu \mathrm{g} \mathrm{ml}^{-1}\right)$, kanamycin $\left(50 \mu \mathrm{g} \mathrm{ml} l^{-1}\right)$, chloramphenicol $\left(30 \mu \mathrm{g} \mathrm{ml}^{-1}\right)$, carbeni-

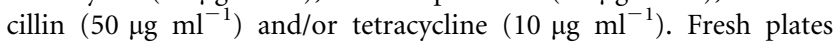
were streaked every week and stored at $4{ }^{\circ} \mathrm{C}$. The $\mu$ aer-ST bacteria were prepared by inoculating one colony into $3 \mathrm{ml} \mathrm{LB-Miller} \mathrm{broth}$ in a $17 \times 100 \mathrm{~mm}, 14 \mathrm{ml}$ polypropylene round-bottom test tube
(Becton Dickinson) with a loose cap, and then incubating at $37{ }^{\circ} \mathrm{C}$ without aeration (no shaking) for $18 \mathrm{~h}$. Aer-LL bacteria were prepared by inoculating one colony into $2 \mathrm{ml} \mathrm{LB}-$ Miller broth, in a $17 \times 100 \mathrm{~mm}, 14 \mathrm{ml}$ polypropylene round-bottom test tube (Becton Dickinson) with a loose cap, and incubating at $37{ }^{\circ} \mathrm{C}$ with aeration (shaking at 225 r.p.m.) for 16-18 h. Thereafter, a $300 \mu \mathrm{l}$ aliquot of this culture was immediately subcultured into $10 \mathrm{ml} \mathrm{LB}-$ Miller broth, in a $150 \mathrm{ml}$ glass Erlenmeyer flask with a loose cap, and incubated at $37{ }^{\circ} \mathrm{C}$ for $3.5 \mathrm{~h}$ with aeration (shaking at 225 r.p.m.).

Measurement of bacterial growth. For measurement of bacterial growth, Salmonella was cultured as described, then samples were taken every hour for $\mathrm{OD}_{600}$ readings in a SmartSpec $3000 \mathrm{spec}-$ trophotometer (Bio-Rad) and diluted in sterile $1 \times \mathrm{PBS}, \mathrm{pH} 7.2$, and plated on LB-Miller agar for enumeration of viable bacteria.

Plasmid stability. Plasmid stabilities in culture, aerated and nonaerated as described, or in infected cells were confirmed by plating on LB Miller agar and by comparing the c.f.u. obtained in the presence $\left(50 \mu \mathrm{g}\right.$ carbenicillin $\mathrm{ml}^{-1}$ ) or absence (no antibiotic) of selection.

Salmonella Affymetrix array. The S. Typhimurium SL1344 (NCTC 13347) genome was first analysed by Integrated Genomics to remove genetic redundancy and provide annotation for intergenic and opposite-strand coding regions using the sequence contigs from the Sanger Institute (www.sanger.ac.uk). The microarray is an 11 micron, 49-5241 format array containing 108166 probe pairs or about 9833 eleven-probe-pair probe sets specific to 4712 ORFs and 5121 intergenic and opposite-strand coding targets (Affymetrix).

Microarray experiments. For each condition ( $\mu$ aer-ST or aer-LL Salmonella) six biological replicates were prepared. Total RNA from each sample was stabilized with RNAProtect (Qiagen). The concentrate was fragmented with a QIAshredder (Qiagen) and total RNA was purified in 96-well format using the RNeasy 96 kit centrifugation system (Qiagen) as described previously (Virtaneva et al., 2005). RNA samples were treated with DNA-free DNase I (Ambion) and sample quality was monitored on Agilent RNA Pico II LabChips (Agilent Technologies). Additionally, possible DNA contamination was tested by quantitative PCR (qPCR; see below). Total RNA $(10 \mu \mathrm{g})$ from each sample was reverse-transcribed to cDNA using $4.5 \mu \mathrm{g}$ random hexamer primers (Invitrogen) and $30 \mathrm{U}$ SuperScript III reverse transcriptase (Invitrogen). RNA was removed by treatment with $0.25 \mathrm{M} \mathrm{NaOH}$ for 30 min at $65^{\circ} \mathrm{C}$ and then neutralized with $1 \mathrm{M} \mathrm{HCl}$. cDNA was purified using a QIAQuick 96 PCR purification kit (Qiagen), quantified and fragmented with $0.6 \mathrm{U}$ DNase I (Roche). An Enzo BioArray Terminal Labelling kit with Biotin-ddUTP (EnzoLite Sciences) was used to label the 3' termini of the fragmented cDNA products. Labelled and fragmented cDNA $(2 \mu \mathrm{g})$ was hybridized to Salmonella GeneChips following a previously described procedure (Virtaneva et al., 2005).

Transcriptome analysis. Affymetrix GeneChip Operating Software (GCOS v1.4, http://www.affymetrix.com) was used to perform the preliminary analysis of the custom chips at the probe-set level. A pivot table with all samples was created including calls, call $P$-value and signal intensities for each gene. The pivot table was then imported into GeneSpring GX 7.3 (Agilent), where hierarchical clustering (condition tree) using a Pearson correlation similarity measure with average linkage was used to produce the dendrogram indicating that biological replicates were grouping together (data not shown). The CEL files were imported into Partek Genomics Suite and quantile normalized to produce a principal component analysis (PCA) plot as a secondary statistical check on biological replicates grouping together. A one-way ANOVA was run from these datasets to produce a false discovery rate (FDR) report of false positive reduced $P$-values for each of the treatments. Once the data had passed all preliminary statistical 
tests, the biological replicates were combined. A custom Microsoft Excel worksheet was then used to combine correlated replicates of all test conditions and controls. Quality filters based upon combined calls and signal intensities were used in the worksheet in order to further evaluate individual gene comparisons. Present and marginal were treated as the same while absent calls were negatively weighted for the filters and dropped completely from quality summations. All individual genes passing the above filters and combined from all usable replicates have the ratios of test:control reported with associated probability of Student's $t$-test values. Significance analysis of microarrays (SAM) (Tusher et al., 2001) was also run within the Excel sheet and a column was added with the results. An additional column was added for Partek's ANOVA $P$-values that passed the FDR.

Gene set enrichment analysis (GSEA). GSEA was performed using gene sets obtained from the Kyoto Encyclopaedia of Genes and Genomes (KEGG; http://www.genome.jp/kegg/pathway.html) and ERGO (Integrated Genomics) (Kanehisa et al., 2008). These databases were curated to include the SPI1 and SPI2 regulon gene sets from previous microarray analysis (Eriksson et al., 2003; Hautefort et al., 2008). The enriched sets were analysed using GSEA (Mootha et al., 2003; Subramanian et al., 2005, 2007) and SAM (Tusher et al., 2001) with 1000 permutations and an FDR of 0.25 for the significance threshold.

qPCR analysis. Briefly, RNA samples were obtained from separate experiments and verified on Agilent RNA Pico II LabChips. For qPCR, the CellsDirect One-Step qRT-PCR kit (Invitrogen) was used according to manufacturer's instructions. Primers and probes for different genes were designed using Primer Express v2.0 software for multiplex qPCR (Applied Biosystems) and 100\% amplification efficiency and compatibility were verified with $S$. Typhimurium genomic DNA. Relative quantification of the gene expression was determined with the comparative threshold $\left(\Delta \Delta C_{\mathrm{T}}\right)$ method (Applied Biosystems). fts $Z$ was chosen as an internal control because no significant variation in expression for this gene was observed under the conditions used [this study and Drecktrah et al. (2006)]. In order to detect the correlation between microarray and qPCR fold changes, the Pearson product-moment correlation coefficient $(r)$ was calculated (using Microsoft Excel).

Transcriptional fusions. A destabilized variant of green fluorescent protein, GFP[LVA], with a half-life of approximately $40 \mathrm{~min}$ in $S$. Typhimurium (data not shown) was used as a reporter of gene expression (Andersen et al., 1998). Promoters from the following six genes were selected to drive $g f p[\mathrm{LVA}]$ expression: $i n v F, \operatorname{prgH}$, ssaG, $s o p B, p i p B$ and fliC. $\mathrm{P}_{i n v F}$ was amplified with the oligonucleotides invF-Xho ( $5^{\prime}$-ccg ctc gag aag aat gag gcg cca tgt- $\left.3^{\prime}\right)$ and invF-Kpn $\left(5^{\prime}\right.$ cgg ggt acc aca acg gcc tgc tcg caa- $3^{\prime}$ ) (engineered restriction sites are underlined). $\mathrm{P}_{\text {prgH }}$ was amplified with prgH-Xho ( $5^{\prime}$-ccg ctc gag ttg taa atg ctc ttt att- $\left.3^{\prime}\right)$ and prgH-Kpn $\left(5^{\prime}\right.$-cgg ggt acc aca aag agt gtt cgg cct- $\left.3^{\prime}\right) . \mathrm{P}_{\text {ssaG }}$ was amplified with ssaH-Xho $\left(5^{\prime}-\mathrm{ccg}\right.$ ctc gag tgg tag ttt ggg act- $\left.3^{\prime}\right)$ and ssaH-Kpn ( $5^{\prime}$-cgg ggt acc ata acc gtt agc gct- $\left.3^{\prime}\right)$. These amplicons were digested with XhoI and $K p n I$ and ligated into SalI/ KpnI-digested pGFP[LVA] (Clontech Laboratories). $\mathrm{P}_{\text {sop } B}$ was amplified with the oligonucleotides PsigD-gfp-XbaF (5'-tgc tct aga tgt tca agc atg gaa- $\left.3^{\prime}\right)$ and PsigD-gfp-Kpn2R (5'-cgt tgt atg gta cct ttt gta gg$\left.3^{\prime}\right) . \mathrm{P}_{p i p B}$ was amplified with PpipB-gfp-XbaF (5'-tgc tct aga cgc att tat tct ggt ata- $\left.3^{\prime}\right)$ and PpipB-gfp-KpnR ( $5^{\prime}$-cgg ggt acc ggc cgc atg caa ata tct- $\left.3^{\prime}\right) . \mathrm{P}_{\text {flic }}$ was amplified with PfliC-gfp-XbaF $\left(5^{\prime}\right.$-tgc tct aga cag tag tta agc gcg- $\left.3^{\prime}\right)$ and PfliC-gfp-KpnR (5' -cgg ggt acc cag agc gga ctg gga- $\left.3^{\prime}\right)$. These three amplicons were digested with $X b a \mathrm{I}$ and $K p n \mathrm{I}$ and ligated into the corresponding sites of pGFP[LVA].

The promoter-gfp $[\mathrm{LVA}]$ fusion cassettes were next inserted into the plasmid pMPM-A $3 \Delta$ Plac, made by removing the lac promoter from
pMPM-A3 (Mayer, 1995). $\mathrm{P}_{\text {lac }}$ was removed by inverse PCR with the oligonucleotides delta Plac-for ( $5^{\prime}$-cgg ggt acc agt cgg gaa acc tgt cgt$3^{\prime}$ ) and delta Plac-rev (5'-gga aca aaa gct ggg tac cgg g- $\left.3^{\prime}\right)$. The resulting amplicon was digested with $K p n \mathrm{I}$ and self-ligated to give pMPM-A3 $\Delta$ Plac. Promoter- $g f p[L V A]$ fusion cassettes were excised from pGFP[LVA] by HindIII digestion and ligated into HindIIIdigested pMPM-A3 $\triangle$ Plac. All fusions are in the opposite direction to the $\alpha$-lac $Z$ gene. The reporter genes are designated: pMPMA3 $\Delta$ Plac PinvF-gfp[LVA]/R, pMPMA3 $\Delta$ Plac P prgH-gfp[LVA]/ $\mathrm{R}, \quad$ MPMA3 $\Delta$ Plac PsopB-gfp[LVA]/R, pMPMA3 $\Delta$ Plac PssaG-gfp $[$ LVA $] / \mathrm{R}, \quad$ pMPMA $3 \Delta$ Plac P $p i p B-g f p[$ LVA $] / \mathrm{R}$ and pMPMA $3 \Delta$ Plac $\mathrm{P} f l i C-g f p[\mathrm{LVA}] / \mathrm{R}$. To construct a negative control reporter fusion, a fragment containing $g f p[\mathrm{LVA}]$ without any promoter was removed from pGFP[LVA] by HindIII digestion and ligated into pMPMA $3 \Delta$ Plac to give pMPMA3 $\Delta$ Plac null- $g f p[$ LVA $] / R$. All fusion sequences were verified by DNA sequencing (National Institute for Allergy and Infectious Diseases genomics facility, Rocky Mountain Laboratories).

Flow cytometry. Aliquots $(100 \mu \mathrm{l})$ of bacterial cultures in a roundbottom 96-well plate (Falcon) were centrifuged at $2250 \mathrm{~g}$ for $6 \mathrm{~min}$, washed with PBS and resuspended in freshly made $1 \%$ paraformaldehyde $(\mathrm{PFA} ; \mathrm{w} / \mathrm{v})$ in PBS. Bacteria were then washed twice in PBS and immunostained with an anti-Salmonella LPS mAb (Meridian Life Science) diluted $(1: 2000)$ in PBS for $10 \mathrm{~min}$. Bacteria were again washed twice with PBS, followed by incubation with a Cy5conjugated donkey anti-mouse antibody (1:1000 in PBS; Jackson ImmunoResearch Laboratories) for $10 \mathrm{~min}$ and two more PBS washes. For all measurements, a BD LSR II flow cytometer (BD Bioscience) was used and results were analysed using FlowJo software (Tree Star).

Electron microscopy. Samples $(1 \mathrm{ml})$ of bacterial culture, containing approximately $6 \times 10^{9}$ or $1.5 \times 10^{9}$ c.f.u. of aer-LL or $\mu$ aer-ST respectively, were centrifuged at $1000 \mathrm{~g}$ for $10 \mathrm{~min}$, washed gently with $1 \mathrm{ml}$ PBS and resuspended in $500 \mu \mathrm{l}$ PBS. Droplets $(10 \mu \mathrm{l})$ were then adsorbed for $5 \mathrm{~min}$ on carbon-coated Formvar grids (Ted Pella). Excess fluids were removed from the grid surface by blotting with filter paper, and the sample was stained for 2 min with $2 \%$ ammonium molybdate in double-distilled water. Excess stain was removed by blotting and the samples were dried at room temperature prior to being viewed at $80 \mathrm{kV}$ in a Hitachi 7500 transmission electron microscope (Hitachi High-Technologies). Images were acquired with a digital camera system (Advanced Microscopy Techniques) and processed with Adobe Photoshop v. 7 (Adobe Systems).

Immunofluorescence detection of flagella and type 1 fimbriae. Bacterial cultures were prepared using either wild-type (WT) $S$. Typhimurium or a $\lg B:: \operatorname{Tn} 10$ mutant, both harbouring the reporter plasmid pMPMA3 $\Delta$ Plac PprgH-gfp[LVA]/R, or a fimAICDHF::kan mutant. Bacteria were collected by centrifugation at $1000 \mathrm{~g}$ for $10 \mathrm{~min}$ and resuspended carefully in PBS. PFA was then added $(1 \% \mathrm{w} / \mathrm{v}$ final concentration) and the sample was incubated for $10 \mathrm{~min}$. Fixed bacteria were washed twice with PBS and stained with mouse antiFliC mAb (1:100; BioLegend) and rabbit anti-Salmonella LPS antibodies (1:300; Difco) or rabbit polyclonal anti-FimA (1:100; provided by Andreas Bäumler) and mouse anti-Salmonella LPS mAb $(1: 2000)$. Secondary antibodies were AlexaFluor 568-conjugated goat anti-mouse antibodies (1:1000; Invitrogen) and Cy5-conjugated donkey anti-rabbit antibodies (1:1000; Jackson ImmunoResearch Laboratories). All antibodies were diluted in $0.1 \%(\mathrm{w} / \mathrm{v})$ saponin, $10 \%(\mathrm{w} / \mathrm{v})$ normal goat serum in PBS (SS-PBS). To label DNA, bacteria were incubated with $1 \mu \mathrm{g}$ Hoechst 33342 solution $\mathrm{ml}^{-1}$ (Invitrogen). After gentle washing with PBS, bacteria were resuspended in PBS and mounted on glass slides using ProLong Gold antifade reagent (Invitrogen). FliC-positive and FimA-positive Salmonella 
were enumerated visually using an upright fluorescence microscope (Nikon Eclipse E800).

Motility assays. Motility assays on semi-solid agar were performed as described previously (Kim \& Surette, 2003) with some modifications Briefly, $0.5 \mu \mathrm{l}$ of overnight cultures were spotted in the middle of a swimming plate (LB-Miller, $0.25 \%$ agar) in duplicate and allowed to dry for $1 \mathrm{~h}$ at room temperature. Plates were incubated at $37^{\circ} \mathrm{C}$ for $6 \mathrm{~h}$ and growth haloes were measured in $\mathrm{mm}$.

Microscopy-based bacterial motility measurements were performed using Salmonella harbouring plasmid pFPV25.1 for the constitutive expression of gfpmut3 under the control of the $r p s M$ promoter (Valdivia \& Falkow, 1996). Salmonella motility in swimming plates was not affected by either the presence of this plasmid or the expression of GFP (Supplementary Fig. S3). $\mu$ aer-ST and aer-LL cultures were diluted $1: 12$ and $1: 30$, respectively, in PBS. Drops $(10 \mu \mathrm{l})$ of bacterial suspension on a glass slide were covered with a coverslip, which was sealed with wax, and the samples were imaged within 5 min. Images were collected using a Nikon Eclipse Ti Perfect Focus inverted microscope fitted with a Nipkow spinning disk, and a $\times 60,1.4$ numerical aperture oil immersion objective (Nikon). Image acquisition by a Photometrics CascadeII camera was controlled by Metamorph software (Molecular Devices). A time-lapse series of 26 sequential images ( $100 \mathrm{~ms}$ exposure) was taken over $5 \mathrm{~s} \quad(n=10$ fields). To identify non-motile Salmonella, i.e. those that remained in the same location in images 1,13 and 26, these three images were overlaid in ImageJ (http://rsb.info.nih.gov/ij/). To enumerate the total number of bacteria in the sample, Salmonella were fixed (1\% PFA) and mounted before imaging ( $n=10$ fields). The percentage of motile bacteria was determined by subtracting from 100 the percentage of total non-motile bacteria.

Invasion and replication assays. These assays were done as described previously (Drecktrah et al., 2006; Steele-Mortimer et al., 1999; Steele-Mortimer, 2008a). Briefly, HeLa cells (human cervical adenocarcinoma epithelial, ATCC CCL-2) were grown in growth medium (GM), consisting of Eagle's medium (Mediatech) supplemented with $10 \% \quad(\mathrm{v} / \mathrm{v})$ heat-inactivated fetal bovine serum (Invitrogen), in a humidified $37{ }^{\circ} \mathrm{C}, 5 \% \mathrm{CO}_{2}$ incubator. HeLa cells were seeded $24 \mathrm{~h}$ prior to infection, either in 24 -well plates at $5 \times 10^{4}$ cells per well or in six-well plates at $2.4 \times 10^{5}$ cells per well. Salmonella were collected by centrifugation at $5900 \mathrm{~g}$ for $2 \mathrm{~min}$, resuspended in Hank's buffered saline solution (HBSS) and used immediately to infect epithelial cells for $10 \mathrm{~min}$ at $37^{\circ} \mathrm{C}$. Inoculum counts were checked by plating on LB agar plates. In some experiments, monolayers were centrifuged at $1000 \mathrm{~g}$ for $5 \mathrm{~min}$ immediately after addition of the bacteria and then incubated for a further $10 \mathrm{~min}$ at $37^{\circ} \mathrm{C}$. Extracellular bacteria were removed by aspiration and monolayers were washed twice with HBSS. Monolayers were then incubated at $37^{\circ} \mathrm{C}$ for $20 \mathrm{~min}$ in $\mathrm{GM}$ after which time $50 \mu \mathrm{g}$ gentamicin $\mathrm{ml}^{-1}$ was added for $30 \mathrm{~min}$ to kill extracellular bacteria. Subsequently GM with $10 \mu \mathrm{g}$ gentamicin $\mathrm{ml}^{-1}$ was added for the remainder of the experiment. Monolayers were lysed in $1 \mathrm{ml} 1 \%$ Triton X-100 (v/v), 0.1\% SDS (w/v) in PBS and viable intracellular bacteria were enumerated by plating on LB agar.

Immunofluorescence microscopy. HeLa cells were plated $24 \mathrm{~h}$ prior to infection on glass coverslips in 24 -well plates $\left(6 \times 10^{4}\right.$ cells per well). To measure lysosomal-associated membrane protein 1 (LAMP1) acquisition by the SCV, infected cells were fixed in $2.5 \%$ PFA (w/v) for $10 \mathrm{~min}$ at $37{ }^{\circ} \mathrm{C}$, then permeabilized and blocked with SS-PBS for $20 \mathrm{~min}$. All antibodies were diluted in SS-PBS. Primary antibodies were mouse anti-human LAMP1 (H4A3; 1:1500; Developmental Studies Hybridoma Bank) and rabbit anti-Salmonella LPS (1:2000; Difco). Secondary antibodies were AlexaFluor 488conjugated goat anti-mouse IgG antibodies and AlexaFluor 568- conjugated goat anti-rabbit $\operatorname{IgG}(1: 800$; Invitrogen). After extensive washing in PBS, coverslips were mounted on glass slides using Mowiol (Sigma-Aldrich). LAMP1-positive SCVs were scored visually using a Nikon Eclipse E800 upright fluorescent microscope.

For quantification of intracellular GFP-positive bacteria, HeLa cells on glass coverslips were infected with Salmonella containing the reporter plasmid constructs. Cells were then fixed in $2.5 \%$ PFA and processed for indirect immunofluorescence microscopy with mouse mAb against Salmonella LPS (1:5000; Meridian Life Science), followed by incubation with a Cy5-conjugated donkey anti-mouse antibody (1:800; Jackson ImmunoResearch Laboratories) to detect extracellular bacteria. Cells were then permeabilized and blocked with SS-PBS and total bacteria were detected with rabbit anti-Salmonella LPS antibodies $(1: 2000$; Difco) followed by AlexaFluor 568conjugated goat anti-rabbit antibodies $(1: 800$; Invitrogen). Samples were mounted as described above. The percentage of intracellular GFP-positive Salmonella was enumerated visually using a Nikon Eclipse E800 upright microscope. All values represent the means \pm SD from at least three independent experiments.

QuantiGene detection of intracellular gene expression. Direct measurement of RNA was performed using the QuantiGene reagent system v. 2.0 (Panomics) according to the manufacturer's directions. Probe sets were custom designed by Panomics and detection efficiency was previously standardized with bacterial cultures from both growth conditions (data not shown). Briefly, HeLa cells in sixwell plates $\left(2.2 \times 10^{5}\right.$ cells per well $)$ were infected at an m.o.i. similar to that used for invasion assays. Infected monolayers were lysed in $0.8 \mathrm{ml}$ QuantiGene lysis buffer supplemented with $150 \mathrm{ng}$ Proteinase $\mathrm{K} \mathrm{ml}^{-1}$ (Panomics), and solubilized by incubation at $65{ }^{\circ} \mathrm{C}$ for $30 \mathrm{~min}$. One-tenth of each sample $(80 \mu \mathrm{l})$ was combined with blocking buffer and probe sets for each gene in a capture plate, followed by incubation at $55{ }^{\circ} \mathrm{C}$ for $16-20 \mathrm{~h}$. The wells were then washed three times with wash buffer $(0.1 \times$ SSC, $0.03 \%$ lithium lauryl sulfate). Signal for the bound mRNA was developed by sequential hybridization with branched DNA and alkaline-phosphatase-conjugated label probe (Panomics) at $55{ }^{\circ} \mathrm{C}$ for $1 \mathrm{~h}$. After three washes with wash buffer, the dioxetane substrate was added to the wells and incubated at $50{ }^{\circ} \mathrm{C}$ for $1 \mathrm{~h}$. Luminescence was measured over $1000 \mathrm{~ms}$ using a Safire ${ }^{2}$ microplate reader (Tecan). Uninfected HeLa cells were used to determine the background signal and this value was subtracted from each sample. To normalize the expression of each gene, nus $G$ was chosen as an internal control because no significant variation of expression for this gene was observed (Eriksson et al., 2003).

\section{RESULTS}

\section{Induction of invasive S. Typhimurium}

In order to induce SPI1 gene expression, we grew Salmonella with aeration overnight and then diluted it in fresh medium and grew with aeration to late exponential phase. Originally we used LB broth containing $5 \mathrm{~g}$ $\mathrm{NaCl} \mathrm{l}^{-1}$ (Steele-Mortimer et al., 1999) but have since found that increasing the $\mathrm{NaCl}$ concentration to $10 \mathrm{~g} \mathrm{l}^{-1}$ (LB-Miller) results in better induction of SPI1 [data not shown and Song et al. (2004)]. Other groups have shown that SPI1 can also be induced in stationary phase even in the absence of aeration. We hypothesized that SPI1 induction under different physiological conditions could affect the outcome of Salmonella-host cell interactions. In order to address this hypothesis, we grew $S$. Typhimurium 
SL1344 in LB-Miller broth, either with aeration to late exponential phase (aer-LL) or without aeration to stationary phase ( $\mu$ aer-ST). As previously shown, growth curves (Fig. 1) show that the bacteria grown with aeration reach stationary phase slightly earlier (approximately $4 \mathrm{~h}$ ) than those grown without aeration and they grow to higher cell densities (Song et al., 2004).

To compare these two cultures, we first did a transcriptome analysis in order to confirm that SPI1 genes are similarly expressed and to detect differences in other gene groups. Using a custom-made microarray, 1009 genes were identified with statistically significant changes in the level of expression. Of these, 517 genes were expressed at a higher level and 492 genes were expressed at a lower level in aer-LL bacteria compared with $\mu$ aer-ST bacteria (see Supplementary Table S1 available with the online version of this paper). These data have been submitted to the NCBI GEO database (http://www.ncbi.nlm.nih.gov/geo/) under

(a)

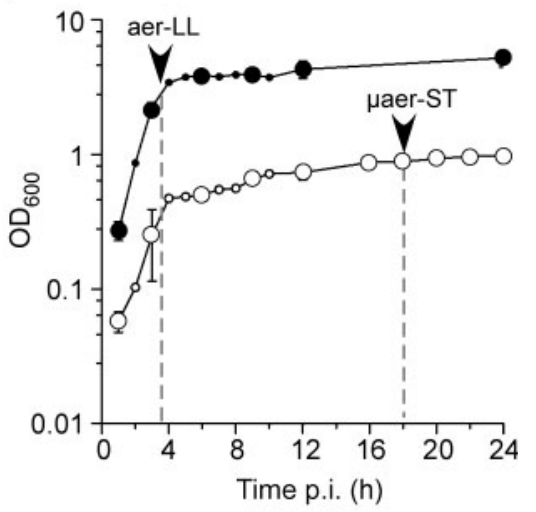

(b)

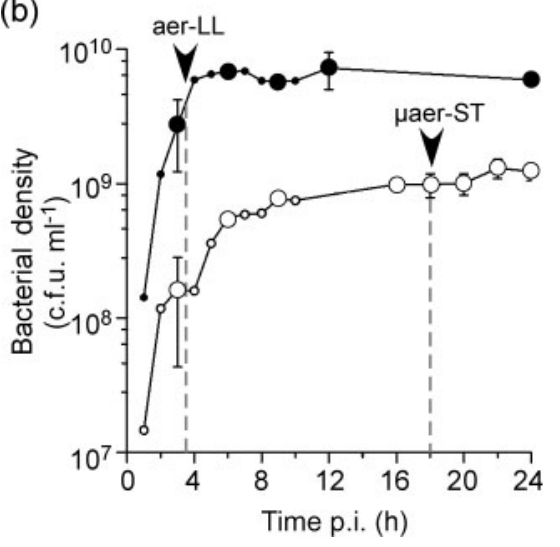

Fig. 1. S. Typhimurium growth curves. Bacteria were grown in LB-Miller broth at $37{ }^{\circ} \mathrm{C}$, with $(\bullet)$ or without $(\bigcirc)$ aeration. Bacterial growth was determined by $\mathrm{OD}_{600}$ (a) or culturable bacterial numbers (b). Arrowheads and dashed vertical lines indicate the time points at which aer-LL and $\mu$ aer-ST bacteria were harvested from aerated and non-aerated cultures, respectively. Larger symbols indicate $n=3$, smaller symbols $n=2$. accession number GSE13343. To identify which functional groups of genes were differentially expressed in aer-LL and $\mu$ aer-ST bacteria, we used GSEA, a computational method that determines whether defined sets of genes show statistically significant, concordant differences between two biological states (Subramanian et al., 2005; Tintle et al., 2008). As predicted, we did not detect significant differences in the SPI1 regulon gene set, whereas flagellar-based motility and chemotaxis gene sets were highly activated in aer-LL bacteria compared with $\mu$ aer-ST bacteria (GSEA rank 1 and 2, data not shown). Comparison of individual genes in these functional groups (Fig. 2) confirmed that the majority of genes in the T3SS1 regulon were similarly expressed in aer-LL and $\mu$ aer-ST bacteria. In contrast, genes involved in flagellar biosynthesis (including $\mathrm{flh}$, flg, fli and flj operons) and chemotaxis (che, mot and $m c p$ ) had higher expression levels in aer-LL bacteria, and genes involved in type 1 fimbriae production and the stress response were more highly expressed in $\mu$ aer-ST bacteria.

We next compared the invasiveness of aer-LL and $\mu$ aerST bacteria using a gentamicin protection assay (Fig. 3). HeLa cells were infected with equivalent c.f.u. from each culture and viable intracellular bacteria were estimated at $1 \mathrm{~h}$ post-infection (p.i.). Cells infected with aer-LL bacteria contained four- to fivefold more Salmonella (approximately $2.8 \times 10^{4}$ per well) than those infected with $\mu$ aer-ST bacteria (approximately $0.6 \times 10^{4}$ per well), which is within the same range as that reported previously under similar conditions (Song et al., 2004). Expression of these data as percentages of the initial inoculum, to account for any differences in inoculum size, showed invasion efficiency of $0.52 \% \pm 0.09$ for aer-LL bacteria and $0.11 \% \pm 0.04$ for $\mu$ aer-ST bacteria. The apparently low invasion efficiency is a reflection of the invasion conditions, since HeLa cells were incubated with a relatively high m.o.i. (approximately 50-60) for a short infection time (10 $\mathrm{min})$. These conditions were selected in order to minimize the effect of environmental changes on gene expression while still internalizing sufficient numbers of bacteria. Given that there are approximately $8 \times 10^{4} \mathrm{HeLa}$ cells per well (data not shown), less than half of the cells are infected, even with the more invasive aer-LL bacteria, demonstrating that these infection conditions are well below saturation levels. Analysis by fluorescence microscopy showed that the distribution of bacteria within cells was not affected by growth condition and that the majority $(>70 \%)$ of infected cells contained fewer than six bacteria (see Supplementary Fig. S1, available with the online version of this paper). Altogether these data show that both growth conditions produce invasive bacteria but aer-LL bacteria are significantly more invasive than $\mu$ aer-ST bacteria.

\section{Single-cell analysis reveals differences in SPI1 gene expression}

Previous studies have shown that, under SPI1-inducing conditions, only a fraction of the population are induced 
(a)

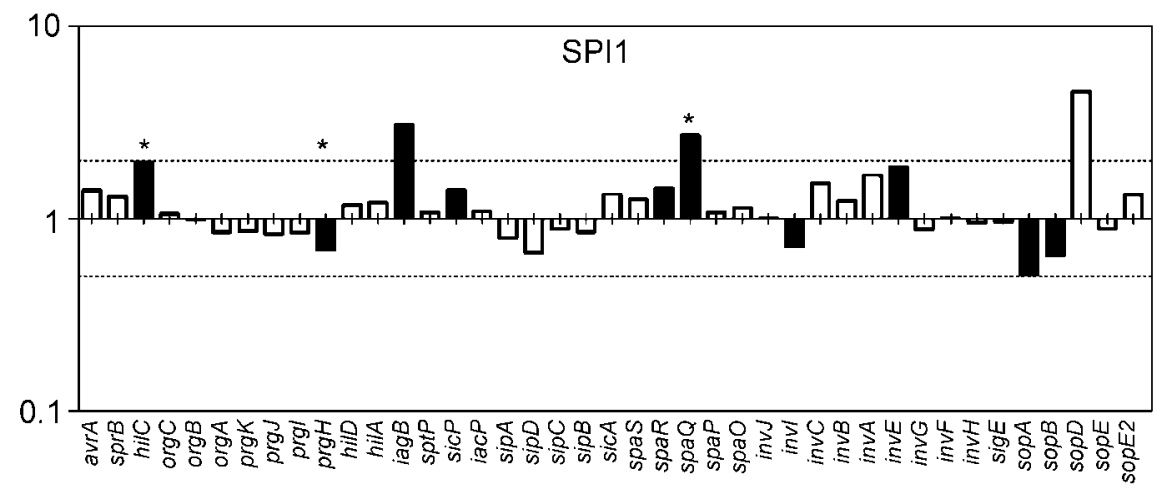

(b)

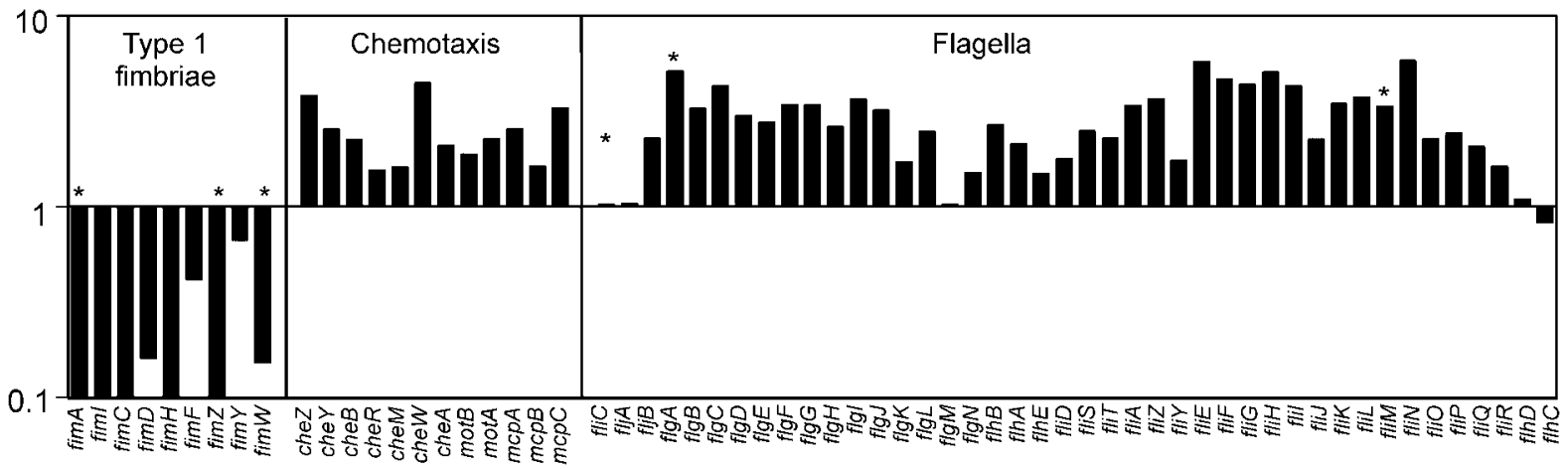

(c)

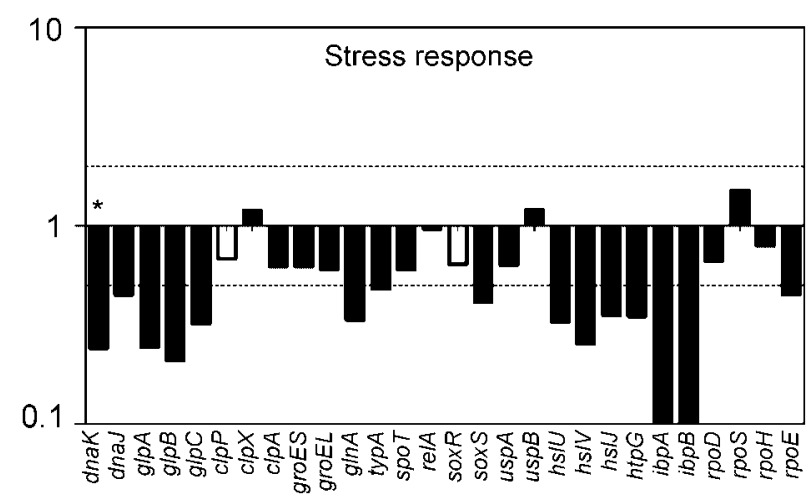

Fig. 2. Relative expression levels of selected genes in $S$. Typhimurium. A value of 1 indicates no detectable difference in expression between aer-LL and $\mu$ aer-ST bacteria, values $>1$ indicate higher expression in aer-LL bacteria and values $<1$ indicate higher expression in $\mu$ aer-ST bacteria. Dotted lines indicate the twofold threshold. (a) SPI1 regulon genes. (b) Motilityassociated genes. (c) Stress-related genes. Black bars denote data that passed the $P$-value threshold. Asterisks indicate data confirmed by qPCR.

and that single-cell experiments are required to characterize the population heterogeneity (Bumann, 2002; Hautefort et al., 2003; Temme et al., 2008). Here, we used transcriptional fusions to a destabilized variant of GFP, GFP[LVA], to identify induced bacteria (Drecktrah et al., 2006). Promoters of three SPI1-regulon genes (invF, $\operatorname{prgH}$ and $\operatorname{sop} B)$ were compared with two SPI2-associated genes ( $s s a G$ and $p i p B$ ) and a flagellin gene $(f l i C)$. Plasmid-borne fusions were introduced into WT S. Typhimurium and the numbers of GFP-positive bacteria were assessed by flow cytometry following growth under aerated and non-aerated conditions (Fig. 4a). Control experiments showed that under these conditions, loss of the plasmid was negligible (see Supplementary Fig. S2, available with the online version of this paper). Initial experiments, in which $\mathrm{P}_{\operatorname{prg} H}$ activity was measured, confirmed that SPI1 induction peaks at approximately $3-4 \mathrm{~h}$ p.i. in aerated culture with approximately $80 \%$ GFP-positive bacteria. In contrast, 
(a)

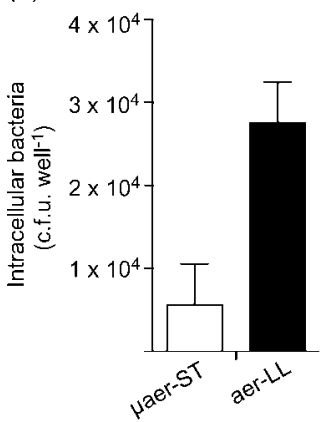

(b)

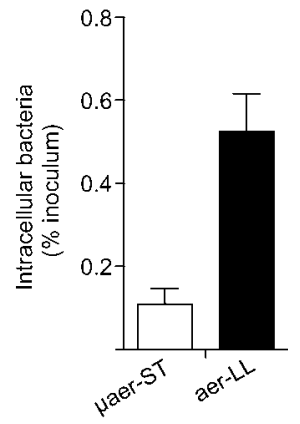

Fig. 3. Invasion of epithelial cells by SPI1-induced bacteria. To directly compare the invasiveness of aer-LL and $\mu$ aer-ST $S$. Typhimurium, HeLa cells were infected for $10 \mathrm{~min}$ at $37^{\circ} \mathrm{C}$ (m.o.i. 50-60). At $1 \mathrm{~h}$ p.i., cells were lysed and intracellular bacteria were enumerated by plating. The means \pm SD from three independent experiments are shown. (a) Invasion expressed as c.f.u. per well. (b) Invasion expressed as \% of inoculum. In both cases $P<0.001$, Student's $t$-test.

in non-aerated culture, GFP-positive bacteria never accounted for more than $40 \%$ of the total population. $\mathrm{P}_{f l i C}$ activity was very similar to $\mathrm{P}_{\text {prgH }}$ in aerated culture but in non-aerated culture revealed very different activation levels at early time points. $\mathrm{P}_{\text {flic }}$ activity was initially high (71 $\pm 7 \%$ GFP-positive bacteria), whereas very little $\mathrm{P}_{\text {prgH }}$ activity could be detected ( $4 \pm 1 \%$ GFP-positive bacteria). Subsequently, $\mathrm{P}_{\text {prgH }}$ activity increased and $\mathrm{P}_{\text {flic }}$ activity decreased too, so that by $8 \mathrm{~h}$, there were similar numbers of GFP-positive bacteria, $26 \pm 7$ and $28 \pm 1 \%$ respectively. Thereafter, there were no significant changes up to $24 \mathrm{~h}$. When plasmids containing an SPI2 gene transcriptional fusion (PssaG- $g f p[\mathrm{LVA}]$ ) or GFP without a promoter (null$g f p[$ LVA] $)$ were used, no significant numbers of GFPpositive bacteria were detected at any time point (Fig. 4 and data not shown). When aer-LL and $\mu$ aer-ST $S$. Typhimurium, harvested from aerated and non-aerated cultures at 3.5 and $18 \mathrm{~h}$ respectively, were directly compared for promoter activities for the three SPI1-regulon genes $i n v F, \operatorname{prgH}$ and $\operatorname{sop} B$, the aer-LL culture contained 82, 81 and $49 \%$ GFP-positive bacteria respectively compared with 40, 39 and $34 \%$ GFP-positive bacteria in the $\mu$ aer-ST culture (Fig. 4b). Similarly, the fliC promoter was induced in $76 \pm 12$ and $36 \pm 4 \%$ of bacteria in aer-LL and $\mu$ aer-ST cultures, respectively. Virtually no activity could be detected in either culture for the SPI2 promoters $\mathrm{P}_{\text {pipB }}$ and $\mathrm{P}_{s s a G}$ or for the null construct. Altogether, single-cell analysis revealed a higher frequency of SPI1-induced bacteria in aer-LL compared with $\mu$ aer-ST bacteria.

To account for the differences between the transcriptome and single-cell data, levels of induction must be higher in SPI1-induced $\mu$ aer-ST bacteria compared with SPI1induced aer-LL bacteria. To investigate this possibility, we compared the GFP intensity profiles in the flow

cytometry data from the above experiments. This revealed that a small, but significant, population of $\mu$ aer-ST Salmonella (2-4\%) had a higher GFP intensity level $\left(\right.$ RFU $>10^{4}$ ) than detected in any aer-LL bacteria (Fig. $4 \mathrm{c}$ ). Thus, although fewer Salmonella are SPI1-induced in the $\mu$ aer-ST compared with the aer-LL culture, a small percentage of 'hyper-induced' SPI1 bacteria in $\mu$ aer-ST cultures results in similar average expression levels of SPI1 genes, as indicated by the transcriptome analysis.

\section{Flagella are required for efficient Salmonella invasion}

Salmonella achieve motility from 5-10 peritrichous, or randomly placed, filamentous flagella that extend from the cell surface. $S$. Typhimurium has two loci encoding different flagellins, $f l i C$ and $f l j B$, the expression of which is governed by a switch mechanism so that only one flagellin is expressed at a time [reviewed by McQuiston et al. (2008)]. Our transcriptome data suggested that $f l j B$ was induced in aer-LL bacteria whereas no difference was detected in $\mathrm{fliC}$ expression (Fig. 2b). However, a fliC mutant was more affected in motility and invasion of HeLa cells compared with a $f l j B$ mutant (data not shown and Supplementary Fig. S3, available with the online version of this paper). Since comparative analysis does not exclude the possibility that $\mathrm{fliC}$ is induced under both conditions, similar to the SPI1-regulon genes, we used the GFP-based transcriptional fusion assay to see if the SPI1induced bacteria are also flagellated. Salmonella bearing the PprgH-gfp[LVA] construct were scored for GFP fluorescence and/or flagella using an anti-FliC antibody. Using this method, $48 \pm 5 \%$ of aer-LL and $23 \pm 3 \%$ of $\mu$ aer-ST bacteria were GFP-positive. Of these SPI1-induced bacteria, $75 \pm 8 \%$ of the aer-LL and $94 \pm 5 \%$ of the $\mu$ aer-ST culture were also FliC-positive, whereas only one-third of the GFP-negative bacteria were FliC-positive. The physical presence of flagella on the surface of both $\mu$ aer-ST and aerLL bacteria was confirmed by electron microscopy (Supplementary Fig. S4, available with the online version of this paper), which also revealed that fimbriae were only present on the surface of $\mu$ aer-ST bacteria.

We hypothesized that the physical presence of flagella may not accurately reflect the functional competence of these structures i.e. motility. To compare the motility of aer-LL and $\mu$ aer-ST Salmonella, we developed a rapid microscopybased assay which allowed us to assess motility within minutes of harvesting the bacteria, using $S$. Typhimurium constitutively expressing GFP (Valdivia \& Falkow, 1996). This assay revealed that motile bacteria predominate in the aer-LL $(76 \pm 12 \%)$ compared with the $\mu$ aer-ST $(33 \pm 16 \%)$ culture (Fig. 5a) in agreement with the higher expression levels of motility and chemotaxis related genes.

The above experiments revealed a correlation between SPI1 expression and motility, with SPI1-induced motile bacteria predominating in the aer-LL culture. We next considered the contribution of flagellar-based motility in invasion of 


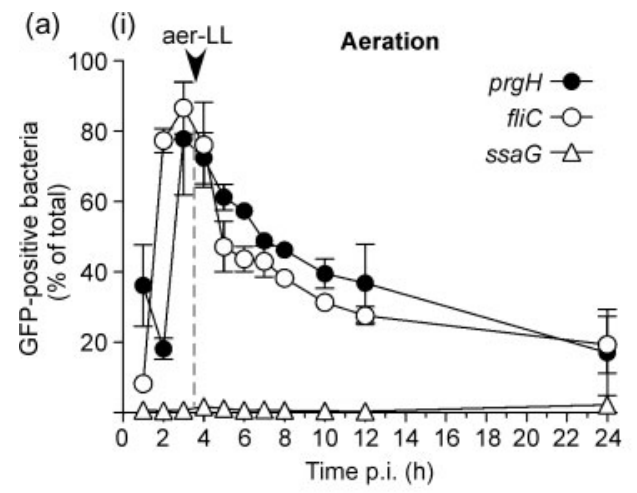

(b)

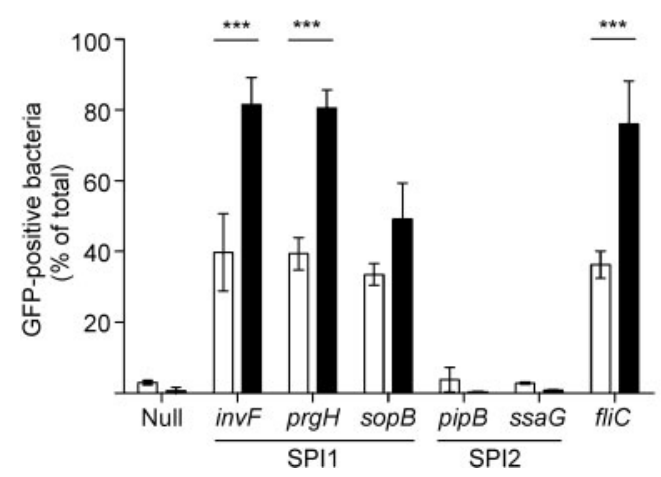

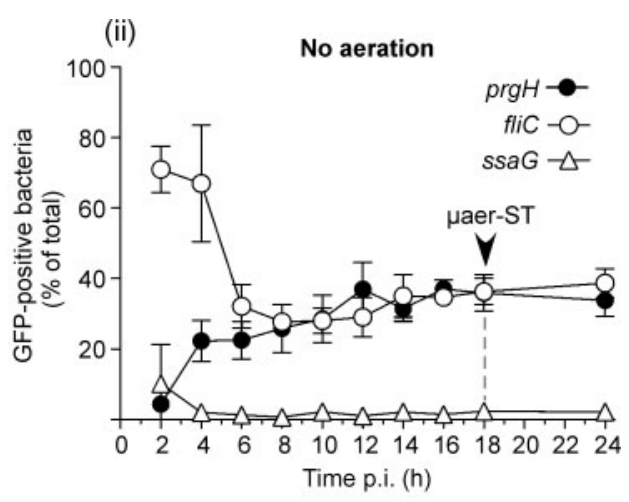

(c)

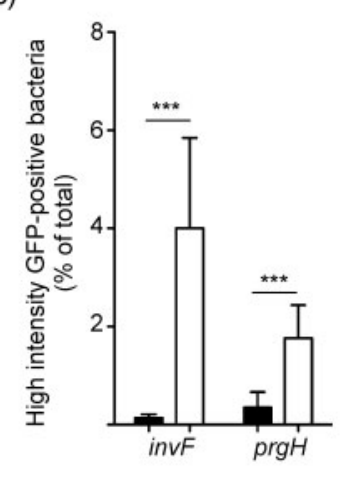

Fig. 4. Single-cell analysis of promoter activity for representative SPI1 and flagellin genes. S. Typhimurium harbouring gfp[LVA] transcriptional fusions to selected promoters were analysed by flow cytometry. (a) Activity of promoters for cultures grown with (i) or without (ii) aeration. Arrowheads indicate the time points at which aer-LL and $\mu$ aer-ST bacteria were harvested. (b) Promoter activity in aer-LL (filled bars) and $\mu$ aer-ST (open bars) bacteria. Comparison of SPI1 regulon genes (prgH, invF and sopB), SPI2 regulon genes (pipB and ssaG), and the flagellin gene fliC. Promoterless $g f p[\mathrm{LVA}]$ (null) was included as a negative control. (c) Comparison of the frequencies of high-intensity GFP $\left(>10^{4}\right.$ relative fluorescent units) expressing bacteria in aer-LL (filled bars) and $\mu$ aer-ST (open bars) bacteria. Shown are means \pm SD from at least three independent experiments. ${ }^{\star \star \star} P<0.001$, Student's $t$-test.

either $\mu$ aer-ST or aer-LL $S$. Typhimurium into HeLa cells. To do this, we compared the invasion efficiency of a nonmotile S. Typhimurium flagellar mutant, fliC: $: \operatorname{Tn} 10$ $f l j B:$ :Mud-Cm, which is deficient for both flagellin proteins, to WT $S$. Typhimurium, as well as a non-invasive $\Delta$ SPI1 mutant (Drecktrah et al., 2006). The absence of flagella and motility in the flagellar mutant was confirmed by electron microscopy and soft agar motility assay (Supplementary Fig. S3 and data not shown). To directly compare the requirement for motility in both cultures, the inoculum size of $\mu$ aer-ST bacteria was increased (fivefold higher m.o.i. compared with aer-LL) so that similar numbers of WT bacteria were internalized (Fig. 5b). Compared with WT, both the SPI1-deletion mutant, which lacks T3SS1 and is invasion defective, and the flagellar mutant had massive defects in the numbers of internalized bacteria (approximately $3 \%$ and $<1 \%$ of WT respectively) (Khoramian-Falsafi et al., 1990). We then confirmed that the invasion deficiency of the flagellar mutant could be overcome by centrifugation to increase contact with host cells (Fig. 5b), since this can compensate for the lack of motility but not the lack of SPI1 (van Asten et al., 2004). Altogether, these data show that flagella-based motility is an important component in the initiation of contact with epithelial cells for both $\mu$ aer-ST and aer-LL Salmonella.

\section{Pre-invasion bacterial growth conditions can affect intracellular replication and intracellular virulence gene expression}

The ability of Salmonella to survive and replicate within host cells is a multifactorial process that can be affected by a variety of bacterial genes [for review see the paper by Ibarra \& Steele-Mortimer (2009)]. Since aer-LL and $\mu$ aerST Salmonella are grown under different conditions and are induced for different gene sets, we next compared the ability of these bacteria to replicate inside HeLa cells. For these experiments, we used the gentamicin protection assay, adjusting the inoculum size to ensure that there was $<1 \%$ difference in the numbers of bacteria internalized 

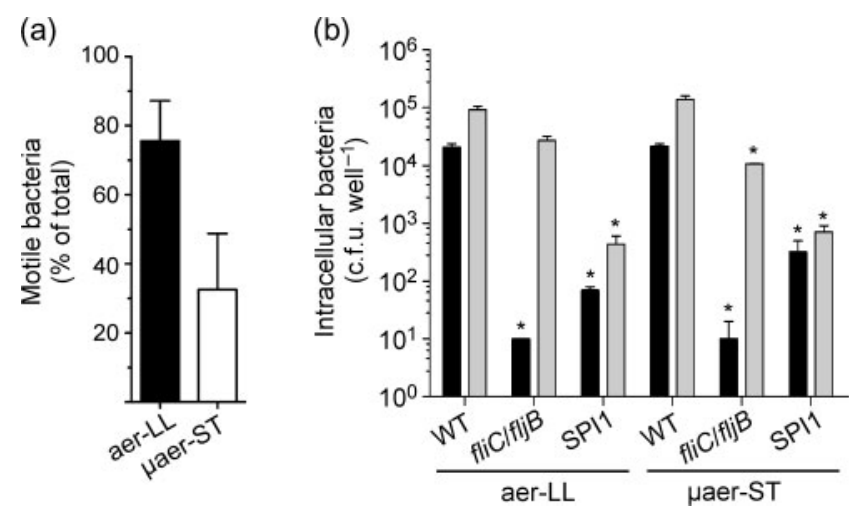

Fig. 5. Flagella-based motility is required for optimal invasion of epithelial cells. (a) Bacterial motility was assessed by fluorescence microscopy using $S$. Typhimurium constitutively expressing GFP. Shown are means $\pm S D$ from three independent experiments. $P<0.05$, Student's $t$-test. (b) Comparison of the role of flagellarbased motility in invasion. HeLa cells were infected with aer-LL or $\mu$ aer-ST S. Typhimurium either with (shaded bars) or without (filled bars) centrifugation. Intracellular bacteria ( $1 \mathrm{~h}$ p.i.) were enumerated by plating. Strains were WT $S$. Typhimurium (WT), fliC: : Tn $10 \mathrm{fljB}:$ :Mud-Cm mutant (fliC/fljB) and a $\Delta$ SPI1:: kan mutant (SPI1). Means $\pm S D$ from at least three independent experiments are shown. ${ }^{*} P<0.05$, Student's $t$-test (compared with WT without centrifugation).

and no significant difference in the intracellular distribution of bacteria at $1 \mathrm{~h}$ p.i. (Supplementary Fig. S1). This is important since even small differences in the numbers of bacteria internalized, as opposed to the invasion efficiency, could be amplified into significant differences once replication is initiated. As shown in Fig. 6(a), intracellular $S$. Typhimurium initiated intracellular replication by $6 \mathrm{~h}$ p.i. irrespective of the pre-invasion growth conditions, but by $8 \mathrm{~h}$, aer-LL bacteria showed a marked increase in replication compared with $\mu$ aer-ST bacteria (51-fold increase versus 10 -fold increase at $1 \mathrm{~h}$ ).
The marked difference in intracellular replication of aer-LL and $\mu$ aer-ST Salmonella suggested that pre-invasion growth conditions can affect the ability of Salmonella to adapt to the intracellular environment. To address this, we first asked whether there was any apparent defect in SCV biogenesis, by following the recruitment of the lysosomal membrane protein LAMP1, which occurs with well-established kinetics (Steele-Mortimer et al., 1999). However, no difference in LAMP1 acquisition could be detected (Fig. 6b) suggesting that the differences in intracellular replication cannot be attributed to overt changes in vacuole biogenesis.

We next considered that intracellular virulence gene expression might be affected by the pre-invasion growth conditions. Previous experiments have shown that SPI1 genes are rapidly downregulated following internalization into host cells (Boddicker \& Jones, 2004; Drecktrah et al., 2006; Knodler et al., 2009), so we used the GFP[LVA] transcriptional fusions to follow this process in individual bacteria following invasion of HeLa cells. As expected, the numbers of SPI1-induced GFP-positive bacteria ( $p r g H$ and $s o p B$ ) rapidly decreased after internalization and by $4 \mathrm{~h}$ p.i., virtually no GFP-positive bacteria could be detected. However, when aer-LL and $\mu$ aer-ST bacteria harbouring the PprgH-gfp[LVA] fusion were compared (Fig. 7a), we observed an apparent delay in downregulation in aer-LL bacteria such that at $0.5 \mathrm{~h}$ p.i., more aer-LL bacteria were GFP-positive ( $80 \pm 5 \%$ compared to $59 \pm 11 \%$ ). A similar, though more dramatic, trend was observed with the PfliC$g f p[\mathrm{LVA}]$ fusion; $82 \pm 7 \%$ of aer-LL bacteria compared with $38 \pm 7 \%$ of $\mu$ aer-ST bacteria were GFP-positive at $0.5 \mathrm{~h}$. In contrast, we did not detect any difference in the downregulation of $\operatorname{sop} B$, presumably because this gene is expressed at lower levels. When intracellular expression of the SPI2 regulon genes $s s a G$ and $p i p B$ was compared, we observed induction in both cases, although there were far fewer GFP-positive bacteria when the PpipB-gfp[LVA] fusion was used, probably due to low expression levels of pipB. Comparison of numbers of GFP-positive bacteria (a)

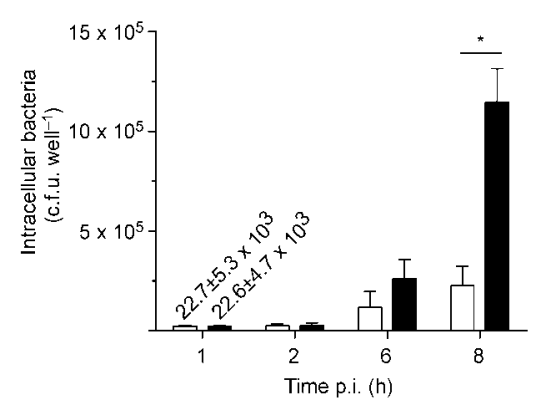

(b)

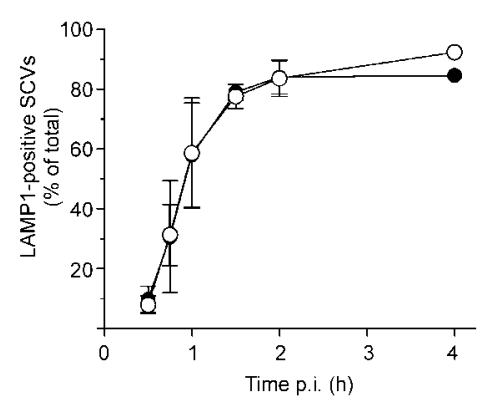

Fig. 6. Intracellular replication is affected by pre-invasion growth conditions. Infected HeLa cells were lysed for enumeration of intracellular $S$. Typhimurium (a) or fixed and processed for immunofluorescence using anti-LPS and antiLAMP1 antibodies (b). To obtain comparable invasion, cells were infected with an m.o.i. of approximately 50-60 for aer-LL and approximately $150-180$ for $\mu$ aer-ST. The numbers of intracellular aer-LL (filled symbols/bars) or $\mu$ aer-ST (open symbols/bars) S. Typhimurium with coincident LAMP1 staining cell were scored visually by fluorescence microscopy. Means \pm SD from three independent experiments are shown. ${ }^{\star} P<0.001$, Bonferroni's post-hoc test. 
again revealed a slight dependence on the pre-invasion growth method, suggesting that post-invasion induction of SPI2 genes is more efficient in aer-LL bacteria. However, this was less dramatic than that seen for the $\mathrm{prgH}$ and $\mathrm{fliC}$ promoters.

Limitations of the plasmid-based GFP transcriptional fusion assay used here are that the presence of plasmid and/or the expression of GFP could affect invasion or the ability of the bacteria to respond to the intracellular environment (J. A. Ibarra, L. A. Knodler and O. SteeleMortimer, unpublished observations; Clark et al., 2009; Knodler et al., 2005). Therefore, we independently confirmed these results by assessing the relative levels of RNA obtained from intracellular WT $S$. Typhimurium (Canales et al., 2006; Flagella et al., 2006). This method uses oligonucleotide probe sets that bind a contiguous region of the target RNA. Unfortunately, technical limitations of probe design made it impossible to make ssaG probes. Instead, we analysed another SPI2 gene, ssaJ, which is in the same operon as ssaG (Lober et al., 2006). Probe sets were first tested on aer-LL and $\mu$ aer-ST bacterial cultures, and gave similar results to quantitative PCR for the SPI1regulon genes, $\operatorname{prgH}$ and $\operatorname{sop} B$, and the flagellin gene $f l i C$ (data not shown). As expected, no SPI2-regulon gene expression was detected in these cultures. In intracellular bacteria, this method confirmed the results obtained with the transcriptional fusion assay for the $\operatorname{prgH}, \operatorname{sopB}$ and $\mathrm{fliC}$ promoters but was unable to recapitulate any significant differences in the SPI2 gene induction (Fig. 7b). Altogether, these gene expression analyses show that the increased multiplication efficiency of aer-LL $S$. Typhimurium inside epithelial cells is associated with higher expression of SPI1 genes at early times post invasion.

\section{DISCUSSION}

S. enterica serovars invade non-phagocytic host cells by inducing membrane ruffling on the host cell surface, a wellcharacterized process that is mediated by effector proteins translocated via T3SS1 (Patel \& Galan, 2005). In vitro, the SPI1 regulon, which encodes T3SS1, can be induced under several different conditions including growth with aeration to late-exponential (aer-LL) and growth without aeration to stationary phase ( $\mu$ aer-ST). While the expression of SPI1 genes under similar conditions has been examined (Croinin \& Dorman, 2007; Mangan et al., 2006; Song et al., 2004; Temme et al., 2008), the effect on pathogen-host interactions of SPI1 induction under different physiological backgrounds has not been addressed. In this study, we examined aer-LL and $\mu$ aer-ST S. Typhimurium cultures, and their ability to interact with cultured epithelial cells, in a comparative analysis using both population-based and single-cell methods. Our main findings are: (i) that preinvasion conditions affect invasion, intracellular replication and post-invasion expression of SPI1 genes; (ii) that singlecell analysis of SPI1 induction reveals differences in aer-LL and $\mu$ aer-ST cultures not revealed by transcriptome analysis; and (iii) that co-expression of SPI1 and flagella is associated with higher invasion levels.

Here, we found that pre-invasion growth conditions can significantly affect the invasiveness of $S$. Typhimurium as well as the ability of the bacteria to replicate intracellularly. In contrast, a recent report showed that, unlike for S. enterica serovar Typhi, growth conditions have no effect on the invasiveness of $S$. Typhimurium (Bishop et al., 2008). The differences in results are doubtless due in part to the methods or strains used, but also, Bishop et al. (2008) did not include late-exponential-phase bacteria in their studies. Previously, we have shown a very strong correlation between late-exponential growth and invasiveness using a different $S$. Typhimurium strain (14028s) (Steele-Mortimer et al., 1999), and here we have used SL1344; however, it is possible that other strains behave differently.

Our single-cell analysis of gene expression revealed significant differences between aer-LL and $\mu$ aer-ST S. Typhimurium in both the frequency of SPI1-induced bacteria and the maximum induction levels, in agreement with previous findings (Passerat et al., 2009; Song et al., 2004), as well as in the expression of flagellar motility. Regulation of the SPI1 regulon is complex and subjected to the actions of a number of factors, which are still not well understood but themselves could be differentially regulated under the conditions described here. Transcriptional regulators necessary for optimal induction in aerobic conditions include HilA, HilC, EnvZ/OmpR and SirA/BarA (Song et al., 2004). Some may be important under both conditions, for example the positive regulator Fis, which under aerobic growth is expressed only in early exponential phase, but is expressed throughout stationary phase in non-aerobic growth conditions (Croinin \& Dorman, 2007). This sustained expression of Fis in non-aerobic conditions would explain why SPI1 is induced in $\mu$ aer-ST bacteria. Another global regulator involved in SPI1 regulation is the integration host factor (IHF), the expression of which peaks in late-exponential and stationary phases and plays a positive role in the expression of SPI1 and flagella in the early late-exponential phase of growth in aerobic conditions (Mangan et al., 2006). This is consistent with our finding that in aer-LL bacteria, SPI1 and flagella genes are highly expressed and a model that proposes co-regulation of invasion and motility genes (Baxter \& Jones, 2005; Kage et al., 2008; Saini et al., 2008). Nevertheless, other groups have found repression of motility under conditions of SPI1-induction and vice versa, and the regulatory connection between motility and virulence remains unclear (Teplitski et al., 2003; Thijs et al., 2007). Regardless, our data clearly define both SPI1 expression and flagellar motility as being required for optimal invasion by Salmonella.

We, and others, have previously shown that the mode of bacterial entry and SPI1-induction can affect the intracellular responses of Salmonella in phagocytic cells (Drecktrah 
(a)
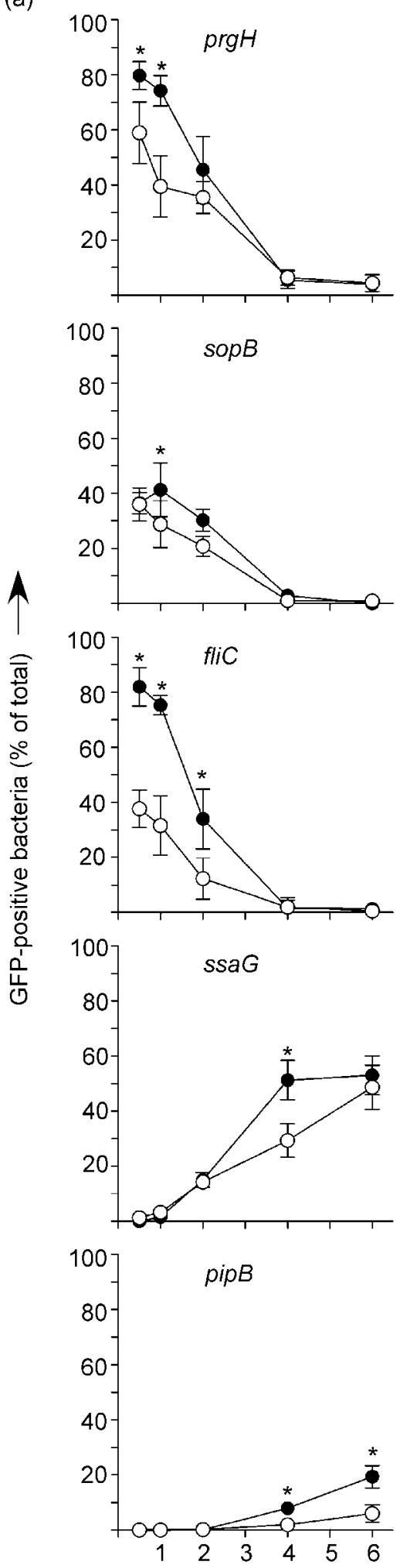

Time p.i. (h) (b)
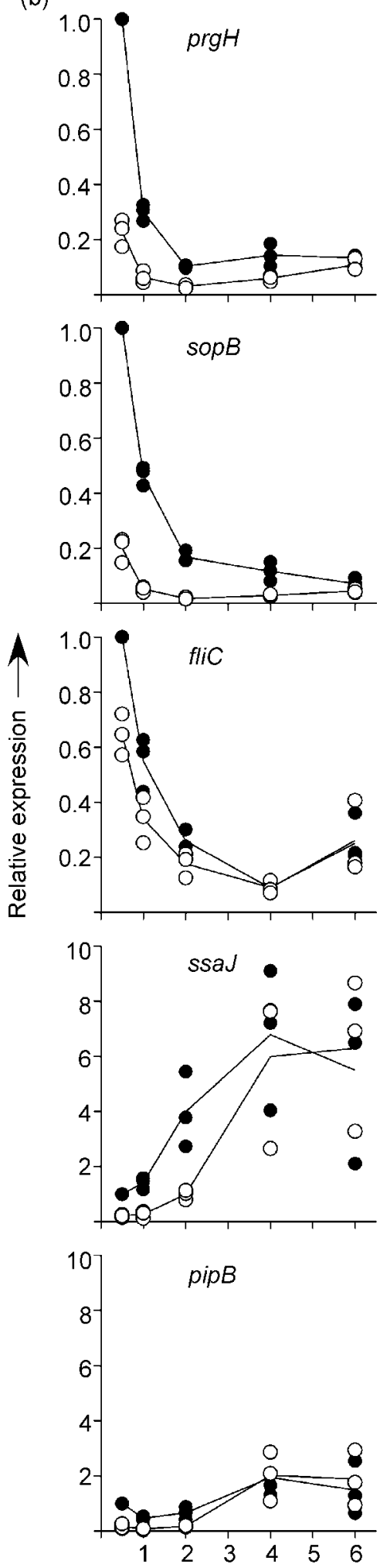

Time p.i. (h)
Fig. 7. Intracellular virulence gene expression can be influenced by pre-invasion growth conditions. (a) gfp [LVA] transcriptional fusions were used to assess promoter activity for $p r g H, \operatorname{sop} B, \operatorname{ssa} G, p i p B$ and fliC following invasion of HeLa cells. GFP-positive 'induced' bacteria were scored visually by fluorescence microscopy. Extracellular $S$. Typhimurium were stained with anti-LPS mAbs before permeabilization and were excluded from analysis. Means $\pm S D$ from at least three separate experiments are shown. ${ }^{*} P<0.05$, two-way ANOVA and Bonferroni's post-hoc analysis. (b) QuantiGene detection of $p r g H, s o p B, s s a J$, pipB and fli $C$ gene expression. The expression of each gene was normalized to nus $G$ as an internal control and then compared to the value for aer-LL bacteria at $30 \mathrm{~min}$. Each symbol represents the mean from one experiment in duplicate. The statistical means from three (prgH, sopB and fliC) or four (ssaJ and pipB) experiments are indicated. Closed symbols, aer-LL; open symbols, $\mu$ aer-ST. 
et al., 2006; van der Velden et al., 2000). Here, however, we report the novel observation that SPI1-induction via different pre-invasion growth conditions can affect gene expression in non-phagocytic cells. Unlike phagocytic cells, non-phagocytic epithelial cells only internalize invasive, T3SS1-induced Salmonella. Accordingly, invasion should select specifically for SPI1-induced bacteria irrespective of the pre-invasion growth conditions and thus, since only SPI1-induced bacteria are internalized, these bacteria should react similarly to the intracellular environment. One caveat is that non-SPI1-induced 'bystander' bacteria can be internalized into the ruffles stimulated by invasive SPI1-induced bacteria (Steele-Mortimer et al., 2002). In order to minimize this possibility, we did not centrifuge the bacteria onto the monolayer and after a brief $10 \mathrm{~min}$ invasion, we immediately removed non-internalized bacteria by washing. Under these conditions, we found that SPI1 genes are downregulated following invasion in agreement with qPCR showing rapidly decreasing $\operatorname{sop} B$ transcript levels in HeLa cells (Knodler et al., 2009) and studies showing that most SopB is translocated early (Patel et al., 2009). A recent study found that rather than being downregulated as reported here, SPI1 is instead induced following invasion of epithelial cells (Hautefort et al., 2008). While it is difficult to reconcile these contradictions, we believe that they are most probably due to differences in methodology, including a centrifugation step to optimize internalization of bacteria, especially since this later step could increase the numbers of 'bystander' non-SPI1induced cells that are internalized. When we compared intracellular expression of SPI1 genes following internalization of either aer-LL or $\mu$ aer-ST bacteria, the aer-LL bacteria exhibited sustained intracellular SPI1 expression that was accompanied by higher intracellular replication. While we have not shown a direct link between intracellular replication and sustained SPI1 expression in this study, effectors translocated by the SPI1-encoded T3SS1 can have significant post-invasion roles, for example, SopB mediates sustained Akt activation in infected epithelial cells (Steele-Mortimer et al., 2000) and also, though to a less obvious extent, SCV biogenesis (Hernandez et al., 2004). Also, despite rapid downregulation of gene expression, the persistence of some T3SS1 effectors, such as SopB, inside host cells has been demonstrated (Drecktrah et al., 2005; Hernandez et al., 2004; Knodler et al., 2009). Overall, our data suggest that aer-LL bacteria are better able to adapt to the intracellular environment than $\mu$ aer-ST bacteria. This could be due to something as simple as the difference in adapting from an oxygen-rich environment (aer-LL) compared with an oxygen-poor environment ( $\mu$ aer-ST) or with multiple combined factors.

Here, we have defined pre-invasion bacterial growth status as a factor that can influence the outcome of Salmonellahost cell interactions in vitro. We conclude that, in the context of host-pathogen interactions, the physiological state of the bacteria should be considered, particularly when different growth conditions can be used for induction of an invasive phenotype.

\section{ACKNOWLEDGEMENTS}

We thank Seth Winfree, Patricia Fuentes, Ron Messer, Alissa Curda, Craig Martens, Greg Farneth, Damon Ellison and Luke Wicke for expert experimental and technical assistance. We are grateful to Ed Miao for kindly providing phages, to Andreas Bäumler for providing phage stock and the anti-FimA antibody, to the Rocky Mountain Laboratories Genomics Unit for DNA sequencing analysis, to members of our lab for their helpful discussions and criticism and to the reviewers for constructive suggestions. This research was supported by the Intramural Research Program (DIR) of the National Institutes of Health (NIH), National Institute for Allergy and Infectious Diseases (NIAID).

\section{REFERENCES}

Andersen, J. B., Sternberg, C., Poulsen, L. K., Bjorn, S. P., Givskov, M. \& Molin, S. (1998). New unstable variants of green fluorescent protein for studies of transient gene expression in bacteria. Appl Environ Microbiol 64, 2240-2246.

Bajaj, V., Lucas, R. L., Hwang, C. \& Lee, C. A. (1996). Co-ordinate regulation of Salmonella typhimurium invasion genes by environmental and regulatory factors is mediated by control of hilA expression. Mol Microbiol 22, 703-714.

Baxter, M. A. \& Jones, B. D. (2005). The fimYZ genes regulate Salmonella enterica Serovar Typhimurium invasion in addition to type 1 fimbrial expression and bacterial motility. Infect Immun 73, 1377-1385.

Behlau, I. \& Miller, S. I. (1993). A PhoP-repressed gene promotes Salmonella typhimurium invasion of epithelial cells. J Bacteriol 175, 4475-4484.

Bishop, A., House, D., Perkins, T., Baker, S., Kingsley, R. A. \& Dougan, G. (2008). Interaction of Salmonella enterica serovar Typhi with cultured epithelial cells: roles of surface structures in adhesion and invasion. Microbiology 154, 1914-1926.

Boddicker, J. D. \& Jones, B. D. (2004). Lon protease activity causes down-regulation of Salmonella pathogenicity island 1 invasion gene expression after infection of epithelial cells. Infect Immun 72, 20022013.

Bumann, D. (2002). Examination of Salmonella gene expression in an infected mammalian host using the green fluorescent protein and two-colour flow cytometry. Mol Microbiol 43, 1269-1283.

Canales, R. D., Luo, Y., Willey, J. C., Austermiller, B., Barbacioru, C. C., Boysen, C., Hunkapiller, K., Jensen, R. V., Knight, C. R. \& other authors (2006). Evaluation of DNA microarray results with quantitative gene expression platforms. Nat Biotechnol 24, 1115-1122.

Clark, L., Martinez-Argudo, I., Humphrey, T. J. \& Jepson, M. A. (2009). GFP plasmid-induced defects in Salmonella invasion depend on plasmid architecture, not protein expression. Microbiology 155, 461-467.

Croinin, T. O. \& Dorman, C. J. (2007). Expression of the Fis protein is sustained in late-exponential- and stationary-phase cultures of Salmonella enterica serovar Typhimurium grown in the absence of aeration. Mol Microbiol 66, 237-251.

Drecktrah, D., Knodler, L. A., Galbraith, K. \& Steele-Mortimer, O. (2005). The Salmonella SPI1 effector SopB stimulates nitric oxide production long after invasion. Cell Microbiol 7, 105-113. 
Drecktrah, D., Knodler, L. A., Ireland, R. \& Steele-Mortimer, O. (2006). The mechanism of Salmonella entry determines the vacuolar environment and intracellular gene expression. Traffic 7, 39-51.

Ellermeier, J. R. \& Slauch, J. M. (2007). Adaptation to the host environment: regulation of the SPI1 type III secretion system in Salmonella enterica serovar Typhimurium. Curr Opin Microbiol 10, 24-29.

Eriksson, S., Lucchini, S., Thompson, A., Rhen, M. \& Hinton, J. C. (2003). Unravelling the biology of macrophage infection by gene expression profiling of intracellular Salmonella enterica. Mol Microbiol 47, 103-118.

Flagella, M., Bui, S., Zheng, Z., Nguyen, C. T., Zhang, A., Pastor, L., Ma, Y., Yang, W., Crawford, K. L. \& other authors (2006). A multiplex branched DNA assay for parallel quantitative gene expression profiling. Anal Biochem 352, 50-60.

Hansen-Wester, I. \& Hensel, M. (2001). Salmonella pathogenicity islands encoding type III secretion systems. Microbes Infect 3, 549559.

Hautefort, I., Proenca, M. J. \& Hinton, J. C. (2003). Single-copy green fluorescent protein gene fusions allow accurate measurement of Salmonella gene expression in vitro and during infection of mammalian cells. Appl Environ Microbiol 69, 7480-7491.

Hautefort, I., Thompson, A., Eriksson-Ygberg, S., Parker, M. L., Lucchini, S., Danino, V., Bongaerts, R. J., Ahmad, N., Rhen, M. \& Hinton, J. C. (2008). During infection of epithelial cells Salmonella enterica serovar Typhimurium undergoes a time-dependent transcriptional adaptation that results in simultaneous expression of three type 3 secretion systems. Cell Microbiol 10, 958-984.

Hernandez, L. D., Hueffer, K., Wenk, M. R. \& Galan, J. E. (2004). Salmonella modulates vesicular traffic by altering phosphoinositide metabolism. Science 304, 1805-1807.

Hoiseth, S. K. \& Stocker, B. A. (1981). Aromatic dependent Salmonella typhimurium are non-virulent and effective as live vaccines. Nature 291, 238-239.

Ibarra, J. A. \& Steele-Mortimer, O. (2009). Salmonella - the ultimate insider. Salmonella virulence factors that modulate intracellular survival. Cell Microbiol 11, 1579-1586.

Jones, B. D. \& Falkow, S. (1994). Identification and characterization of a Salmonella typhimurium oxygen-regulated gene required for bacterial internalization. Infect Immun 62, 3745-3752.

Kage, H., Takaya, A., Ohya, M. \& Yamamoto, T. (2008). Coordinated regulation of expression of Salmonella pathogenicity island 1 and flagellar type III secretion systems by ATP-dependent ClpXP protease. J Bacteriol 190, 2470-2478.

Kanehisa, M., Araki, M., Goto, S., Hattori, M., Hirakawa, M., Itoh, M., Katayama, T., Kawashima, S., Okuda, S. \& other authors (2008). KEGG for linking genomes to life and the environment. Nucleic Acids Res 36, D480-D484.

Khoramian-Falsafi, T., Harayama, S., Kutsukake, K. \& Pechere, J. C. (1990). Effect of motility and chemotaxis on the invasion of Salmonella typhimurium into HeLa cells. Microb Pathog 9, 47-53.

Kim, W. \& Surette, M. G. (2003). Swarming populations of Salmonella represent a unique physiological state coupled to multiple mechanisms of antibiotic resistance. Biol Proced Online 5, 189-196.

Knodler, L. A., Bestor, A., Ma, C., Hansen-Wester, I., Hensel, M., Vallance, B. A. \& Steele-Mortimer, O. (2005). Cloning vectors and fluorescent proteins can significantly inhibit Salmonella enterica virulence in both epithelial cells and macrophages: implications for bacterial pathogenesis studies. Infect Immun 73, 7027-7031.

Knodler, L. A., Winfree, S., Drecktrah, D., Ireland, R. \& SteeleMortimer, O. (2009). Ubiquitination of the bacterial inositol phosphatase, SopB, regulates its biological activity at the plasma membrane. Cell Microbiol 11, 1652-1670.

Lee, C. A. \& Falkow, S. (1990). The ability of Salmonella to enter mammalian cells is affected by bacterial growth state. Proc Natl Acad Sci U S A 87, 4304-4308.

Lober, S., Jackel, D., Kaiser, N. \& Hensel, M. (2006). Regulation of Salmonella pathogenicity island 2 genes by independent environmental signals. Int J Med Microbiol 296, 435-447.

Mangan, M. W., Lucchini, S., Danino, V., Croinin, T. O., Hinton, J. C. \& Dorman, C. J. (2006). The integration host factor (IHF) integrates stationary-phase and virulence gene expression in Salmonella enterica serovar Typhimurium. Mol Microbiol 59, 1831-1847.

Marcus, S. L., Brumell, J. H., Pfeifer, C. G. \& Finlay, B. B. (2000). Salmonella pathogenicity islands: big virulence in small packages. Microbes Infect 2, 145-156.

Mayer, M. P. (1995). A new set of useful cloning and expression vectors derived from pBlueScript. Gene 163, 41-46.

McGhie, E. J., Brawn, L. C., Hume, P. J., Humphreys, D. \& Koronakis, V. (2009). Salmonella takes control: effector-driven manipulation of the host. Curr Opin Microbiol 12, 117-124.

McQuiston, J. R., Fields, P. I., Tauxe, R. V. \& Logsdon, J. M., Jr (2008). Do Salmonella carry spare tyres? Trends Microbiol 16, 142-148.

Miao, E. A., Alpuche-Aranda, C. M., Dors, M., Clark, A. E., Bader, M. W., Miller, S. I. \& Aderem, A. (2006). Cytoplasmic flagellin activates caspase-1 and secretion of interleukin $1 \beta$ via Ipaf. Nat Immunol 7, 569-575.

Mootha, V. K., Lindgren, C. M., Eriksson, K. F., Subramanian, A., Sihag, S., Lehar, J., Puigserver, P., Carlsson, E., Ridderstrale, M. \& other authors (2003). PGC- $1 \alpha$-responsive genes involved in oxidative phosphorylation are coordinately downregulated in human diabetes. Nat Genet 34, 267-273.

Passerat, J., Got, P., Dukan, S. \& Monfort, P. (2009). Respective roles of culturable and viable-but-nonculturable cells in the heterogeneity of Salmonella enterica serovar typhimurium invasiveness. Appl Environ Microbiol 75, 5179-5185.

Patel, J. C. \& Galan, J. E. (2005). Manipulation of the host actin cytoskeleton by Salmonella - all in the name of entry. Curr Opin Microbiol 8, 10-15.

Patel, J. C., Hueffer, K., Lam, T. T. \& Galan, J. E. (2009). Diversification of a Salmonella virulence protein function by ubiquitin-dependent differential localization. Cell 137, 283-294.

Saini, S., Brown, J. D., Aldridge, P. D. \& Rao, C. V. (2008). FliZ is a posttranslational activator of FlhD4C2-dependent flagellar gene expression. J Bacteriol 190, 4979-4988.

Schiemann, D. A. \& Shope, S. R. (1991). Anaerobic growth of Salmonella typhimurium results in increased uptake by Henle 407 epithelial and mouse peritoneal cells in vitro and repression of a major outer membrane protein. Infect Immun 59, 437-440.

Song, M., Kim, H. J., Kim, E. Y., Shin, M., Lee, H. C., Hong, Y., Rhee, J. H., Yoon, H., Ryu, S. \& other authors (2004). ppGpp-dependent stationary phase induction of genes on Salmonella pathogenicity island 1. J Biol Chem 279, 34183-34190.

Steele-Mortimer, O. (2008a). Infection of epithelial cells with Salmonella enterica. Methods Mol Biol 431, 201-212.

Steele-Mortimer, O. (2008b). The Salmonella-containing vacuole moving with the times. Curr Opin Microbiol 11, 38-45.

Steele-Mortimer, O., Meresse, S., Gorvel, J. P., Toh, B. H. \& Finlay, B. B. (1999). Biogenesis of Salmonella typhimurium-containing vacuoles in epithelial cells involves interactions with the early endocytic pathway. Cell Microbiol 1, 33-49. 
Steele-Mortimer, O., Knodler, L. A., Marcus, S. L., Scheid, M. P., Goh, B., Pfeifer, C. G., Duronio, V. \& Finlay, B. B. (2000). Activation of Akt/ protein kinase B in epithelial cells by the Salmonella typhimurium effector sigD. J Biol Chem 275, 37718-37724.

Steele-Mortimer, O., Brumell, J. H., Knodler, L. A., Meresse, S., Lopez, A. \& Finlay, B. B. (2002). The invasion-associated type III secretion system of Salmonella enterica serovar Typhimurium is necessary for intracellular proliferation and vacuole biogenesis in epithelial cells. Cell Microbiol 4, 43-54.

Subramanian, A., Tamayo, P., Mootha, V. K., Mukherjee, S., Ebert, B. L., Gillette, M. A., Paulovich, A., Pomeroy, S. L., Golub, T. R. \& other authors (2005). Gene set enrichment analysis: a knowledgebased approach for interpreting genome-wide expression profiles. Proc Natl Acad Sci U S A 102, 15545-15550.

Subramanian, A., Kuehn, H., Gould, J., Tamayo, P. \& Mesirov, J. P. (2007). GSEA-P: a desktop application for Gene Set Enrichment Analysis. Bioinformatics 23, 3251-3253.

Temme, K., Salis, H., Tullman-Ercek, D., Levskaya, A., Hong, S. H. \& Voigt, C. A. (2008). Induction and relaxation dynamics of the regulatory network controlling the type III secretion system encoded within Salmonella pathogenicity island 1. J Mol Biol 377, $47-61$.

Teplitski, M., Goodier, R. I. \& Ahmer, B. M. (2003). Pathways leading from BarA/SirA to motility and virulence gene expression in Salmonella. J Bacteriol 185, 7257-7265.

Thijs, I. M., De Keersmaecker, S. C., Fadda, A., Engelen, K., Zhao, H., McClelland, M., Marchal, K. \& Vanderleyden, J. (2007). Delineation of the Salmonella enterica serovar Typhimurium HilA regulon through genome-wide location and transcript analysis. J Bacteriol 189, 4587-4596.
Tintle, N. L., Best, A. A., DeJongh, M., Van Bruggen, D., Heffron, F., Porwollik, S. \& Taylor, R. C. (2008). Gene set analyses for interpreting microarray experiments on prokaryotic organisms. BMC Bioinformatics 9, 469.

Tusher, V. G., Tibshirani, R. \& Chu, G. (2001). Significance analysis of microarrays applied to the ionizing radiation response. Proc Natl Acad Sci U S A 98, 5116-5121.

Valdivia, R. H. \& Falkow, S. (1996). Bacterial genetics by flow cytometry: rapid isolation of Salmonella typhimurium acid-inducible promoters by differential fluorescence induction. Mol Microbiol 22, 367-378.

van Asten, F. J., Hendriks, H. G., Koninkx, J. F. \& van Dijk, J. E. (2004). Flagella-mediated bacterial motility accelerates but is not required for Salmonella serotype Enteritidis invasion of differentiated Caco-2 cells. Int J Med Microbiol 294, 395-399.

van der Velden, A. W., Lindgren, S. W., Worley, M. J. \& Heffron, F. (2000). Salmonella pathogenicity island 1-independent induction of apoptosis in infected macrophages by Salmonella enterica serotype typhimurium. Infect Immun 68, 5702-5709.

Virtaneva, K., Porcella, S. F., Graham, M. R., Ireland, R. M., Johnson, C. A., Ricklefs, S. M., Babar, I., Parkins, L. D., Romero, R. A. \& other authors (2005). Longitudinal analysis of the group A Streptococcus transcriptome in experimental pharyngitis in cynomolgus macaques. Proc Natl Acad Sci U S A 102, 9014-9019.

Weening, E. H., Barker, J. D., Laarakker, M. C., Humphries, A. D., Tsolis, R. M. \& Baumler, A. J. (2005). The Salmonella enterica serotype Typhimurium $l p f, b c f, s t b$, stc, std, and sth fimbrial operons are required for intestinal persistence in mice. Infect Immun 73, 33583366.

Edited by: D. L. Gally 